\title{
Schistosomiasis control program in the state of Minas Gerais in Brazil
}

\author{
Sandra Costa Drummond ${ }^{1 /+}$, Sílvio Roberto Sousa Pereira ${ }^{2}$, Luciana Cristina dos Santos Silva ${ }^{2}$, \\ Carlos Maurício de Figueiredo Antunes ${ }^{2}$, José Roberto Lambertucci ${ }^{2}$
}

${ }^{1}$ Secretaria de Saúde do Estado de Minas Gerais, Belo Horizonte, MG, Brasil ²Serviço de Doenças Infecciosas e Parasitárias, Faculdade de Medicina, Universidade Federal de Minas Gerais, Belo Horizonte, MG, Brasil

\begin{abstract}
The Schistosomiasis Control Program (PCE) was implemented in Minas Gerais (MG) in 1984. In 1999, the state started the investigation and control of schistosomiasis in 470 municipalities. The aim of the present paper is to report the evolution of this Program from 1984-2007. The program included a coproscopic survey carried out in the municipalities of known endemic areas using a quantitative method. Positives were treated with praziquantel and given a program of health education. The information for this study was obtained from data collected and stored by the Health State Department. From 2003-2007, 2,643,564 stool examinations resulted in 141,284 positive tests for Schistosoma mansoni (5.3\%). In the first evaluation after treatment, a decrease in the number of municipalities with prevalence over $10 \%$ was documented. In one village, selected for a more detailed evaluation, the percentage of positive tests decreased from $14.9 \%$ in the baseline survey to $5.3 \%$ after treatment. A reference centre for patients with severe schistosomiasis was created in Belo Horizonte, MG. Based on our findings, we believe that the implementation of PCE in MG is on the right path and in due time these new initiatives will provide desirable results.
\end{abstract}

Key words: schistosomiasis - prevalence - Minas Gerais - control program - hepatosplenic schistosomiasis

In Brazil, schistosomiasis was first described by Pirajá da Silva in 1908 and it is still considered a major public health problem due to the extent of the transmission area. The number of carriers, severe cases (hepatosplenics, neuroschistosomiasis, acute form, liver abscesses, glomerulonephritis, among others) and deaths caused by the disease represent a burden on the economy of developing countries (Lambertucci 1993, Lambertucci et al. 2000, 2001, 2007).

In 1975, the Special Schistosomiasis Control Program (PECE) was initiated by the Ministry of Health (Machado 1982). In 1988, it was incorporated into the routine of the Ministry, lost its special status (high priority) and became the Schistosomiasis Control Program (PCE). Beginning in 1993, PCE was decentralised. Currently, the municipalities are responsible for field activities and the states coordinate their actions. The Federal Government establishes the regulations and sets the goals, supplies material and offers technical training for personnel and financial support.

Minas Gerais (MG) has adhered to PCE regulations since 1983 , however, $70 \%$ of the infected cases in the country are found in MG and Bahia (Amaral \& Porto 1994, Drummond et al. 2006). In MG, 523 out of the 853 municipalities (61\%) have active transmission of schistosomiasis and a population of 10,870,063 living in endemic areas (Fig. 1). The state is divided into the following macro-regions: north, northeast, northwest, northeast, Jequitinhonha, east, southeast, west, central, south, central-south, east-south, north triangle, south triangle.

+ Corresponding author: sandra.drummond@saude.gov.br Received 21 May 2009

Accepted 18 December 2009
The first comprehensive, and most important, survey on the prevalence of schistosomiasis in Brazil was conducted by Pellon and Teixeira (1950). In MG, $279 \mathrm{mu}-$ nicipalities were subjected to 162,491 stool examinations using a concentration method (school age children) and 7,997 samples were found to be infected by Schistosoma mansoni (4.9\%). The Mucuri valley (northeast of MG) presented the highest prevalence, which was over 50\% (Lambertucci et al. 1987).

Twenty-seven years later, Katz et al. (1978) reported the second survey in MG, using a quantitative method for stool examination. The prevalence increased to $9.6 \%$ and the Mucuri valley maintained the highest prevalence in the state (Lambertucci et al. 1987).

The aim of the present paper is to report the evolution of the program of schistosomiasis control and the prevalence of the disease in MG from 1984-2007.

\section{PATIENTS, MATERIALS AND METHODS}

The PCE was implemented in MG in 1984 in five municipalities north of the state. From 1984-1990, the program was administered by the Superintendência de Campanhas de Saúde Pública. Then, the National Health Foundation took charge of the PCE and, in the next nine years, the activities of control were extended to several municipalities in the state. Decentralisation began in 1999, and the Health Service of the state and the equivalent Health Services in every town were obligated to carry out the activities by themselves. That meant that each town was made responsible for the control of the diseases affecting their population. An estimated amount of money is provided each year to cover the expenses from health problems in the community. Notice that no significant alterations of the national directives were made in the control program conducted in MG. 


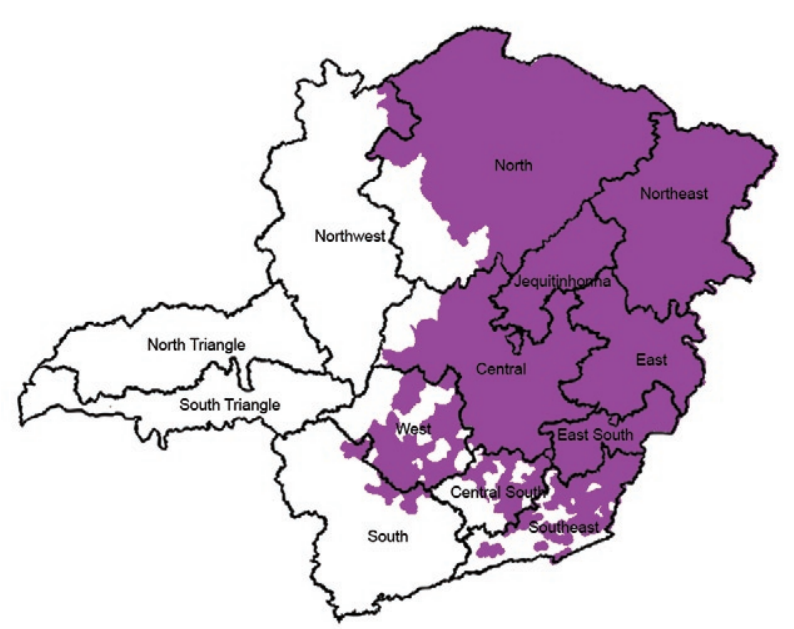

Fig. 1: area endemic for schistosomiasis in Minas Gerais, Brazil.

From 1999 onwards, MG started the investigation and control of schistosomiasis in 470 municipalities following the Ministry of Health directives. Local health personnel (health agents) were trained to do the required activities.

A comprehensive coproscopic survey was carried out in the municipalities of previously known endemic areas. The quantitative Kato-Katz method was used (1 slide per person). Positives were treated with praziquantel $(50 \mathrm{mg} / \mathrm{kg}$ for adults and $60 \mathrm{mg} / \mathrm{kg}$ for children, body weight, single dose). A program of education for health and prevention was also implemented.

The first survey was followed by an evaluation (evaluation 1). In the areas subjected to treatment (where the prevalence decreased below $10 \%$ ), control of the program was assumed by the Local Primary Health Care Services and the stools were obtained by passive demand. In the municipalities with prevalence over $10 \%$, the survey included the whole population. Prevalence (monitoring of transmission) was defined by assessing a databank containing information obtained by compulsory notification of positives. Analysis of the data was supervised by trained epidemiologists in the municipality and quality control was performed by the State Health Department.

Statistical analysis - The information for this study was obtained from the data collected by the Health State Department and stored in a databank using appropriate software (Epi Data 3.1). Chi-square was used for comparison of categorical variables. The initial survey and the first evaluation after mass chemotherapy (evaluation 1) were considered independent events because the identification of volunteers was not available. A significance level of 0.05 was considered throughout the analysis and maps were constructed using the TabWin Program (DATASUS/Ministério da Saúde).

\section{RESULTS}

Prevalence and worm burden - Between 1984-2007 the program of schistosomiasis control was started in $470 \mathrm{mu}-$ nicipalities, but only 256 completed the first survey (identification of subjects and stool examination - census). In 112



Fig. 2: prevalence of schistosomiasis infection in 256 municipalities of Minas Gerais, Brazil in the first survey launched in 1984.

TABLE I

Prevalence of schistosomiasis infection in 256 municipalities in the first survey and 81 in the evaluation 1 after treatment, Minas Gerais, Brazil, 1984-2007

\begin{tabular}{lcc}
\hline Prevalence $(\%)$ & $\begin{array}{c}\text { First survey } \\
\mathrm{n}^{a}=256(\%)\end{array}$ & $\begin{array}{c}\text { Evaluation 1 } \\
\mathrm{n}^{a}=81(\%)\end{array}$ \\
\hline$<10$ & $112(44)$ & $48(59)$ \\
$10-20$ & $92(36)$ & $22(27)$ \\
$>20$ & $52(20)$ & $11(14)$ \\
\hline
\end{tabular}

$a$ : number of participating municipalities; Chi-square $2_{\mathrm{gl}}=6.41$, $\mathrm{p}<0.05$; orthogonal contrasts: $1: 10-20$ vs. $>20$ Chi-square $1_{\mathrm{gl}}=0.09, \mathrm{p}=0.763 ; 2:<10$ vs. others Chi-square $1_{\mathrm{gl}}=5.94$, $\mathrm{p}=0.015$.

$(44 \%)$, prevalence was $<10 \%$, in $92(36 \%)$, it ranged from $10-20 \%$ and, in $52(20 \%)$, it was over $20 \%$ (Fig. 2 ).

Ninety percent of the population with $S$. mansoni infection were treated after the first survey. Eighty-one out of the 256 municipalities (32\%) completed the second survey (evaluation 1). In 48 of the 81 (59\%), prevalence was $<10 \%$, in $22(27 \%)$, it ranged from $10-20 \%$ and, in 11 (14\%), the prevalence was over 20\% (Fig. 3, Table I).

Between 2003-2007, 2,643,564 parasitological stool examinations were conducted in MG and 141,284 subjects were found eliminating eggs of S. mansoni in their stool (5.3\%). Of these subjects, 130,789 were treated for schistosomiasis with praziquantel.

Amparo da Serra, a village in MG, was selected as an example of the PCE activities. The percentage of positives in the baseline survey (14.3\%) decreased to 5.3\% after treatment in evaluation 1 (5.3\%) (Table II).

A constant decrease in the percentage of positives independent of the groups with different egg counts was observed in the first evaluation after treatment (Table III, Fig. 4A). 
TABLE II

Egg burden, number of people infected at baseline and first evaluation after treatment in Amparo da Serra, Minas Gerais, Brazil, 1996-2003

\begin{tabular}{|c|c|c|c|}
\hline & $\begin{array}{c}\text { Baseline survey } \\
\text { 1996-1998 }\end{array}$ & $\begin{array}{c}\text { Evaluation } 1 \\
2002-2003\end{array}$ & $\mathrm{p}$ \\
\hline People examined & 4,334 & 5,356 & \\
\hline Positives & 621 & 282 & \\
\hline Percentage of positives & 14.3 & 5.3 & $<0.01$ \\
\hline Egg count (eggs/g) & $\mathrm{n}(\%)$ & $\mathrm{n}(\%)$ & \\
\hline $1-99$ & $307(7.1)$ & $182(3.4)$ & \\
\hline $100-399$ & $185(4.3)$ & $71(1.3)$ & \\
\hline$>400$ & $129(3)$ & $29(0.6)$ & \\
\hline
\end{tabular}

TABLE III

Prevalence of schistosomiasis infection in 81 municipalities in the first survey and in evaluation 1 after treatment, Minas Gerais, Brazil, 1984-2007

\begin{tabular}{lcc}
\hline $\begin{array}{c}\text { Prevalence } \\
(\%)\end{array}$ & $\begin{array}{c}\text { First survey } \\
\mathrm{n}^{a}=81(\%)\end{array}$ & $\begin{array}{c}\text { Evaluation } 1 \\
\mathrm{n}^{a}=81(\%)\end{array}$ \\
\hline$<10$ & $22(27)$ & $48(59)$ \\
$10-20$ & $33(41)$ & $22(27)$ \\
$>20$ & $26(32)$ & $11(14)$ \\
\hline
\end{tabular}

$a$ : number of participating municipalities; Chi-square $2_{\mathrm{gl}}=17.9$, $\mathrm{p}=0.0001$; orthogonal contrasts: $1: 10-20 \mathrm{vs.}>20$ Chi-square $1_{\mathrm{g} 1}=1.01, \mathrm{p}=0.31 ; 2:<10$ vs. others Chi-square $1_{\mathrm{gl}}=17.0$, $\mathrm{p}=0.00004$.

When prevalence of schistosomiasis decreases below $10 \%$, the municipality is placed under surveillance. In 2005, 26 municipalities north of MG were placed under the control of Primary Health Care. Routine stool examinations revealed the following number of infected inhabitants: in $2005,18,054$ subjects $(0.3 \%)$, in 2006 , 18,670 subjects $(0.3 \%)$ and in $2007,15,945$ subjects (0.2\%) (Fig. 4B).

Schistosomiasis morbidity - An evaluation of morbidity caused by schistosomiasis in MG was implemented in September 2002. A reference centre in Belo Horizonte, MG at the Orestes Diniz Outpatient Clinic (School of Medicine, Federal University of Minas Gerais) became responsible for diagnosing and caring for patients with complicated schistosomiasis. From September 2002-April 2008, 102 patients with hepatosplenic schistosomiasis and 61 with schistosomal myeloradiculopathy were evaluated in this reference centre.

In 2007, the National Centre of Notification of Diseases received a report of eight cases of schistosomal myeloradiculopathy and one report of schistosomal pulmonary hypertension. As of 16 May 2008, the notification of new cases and the investigation of the severe forms of schisto-

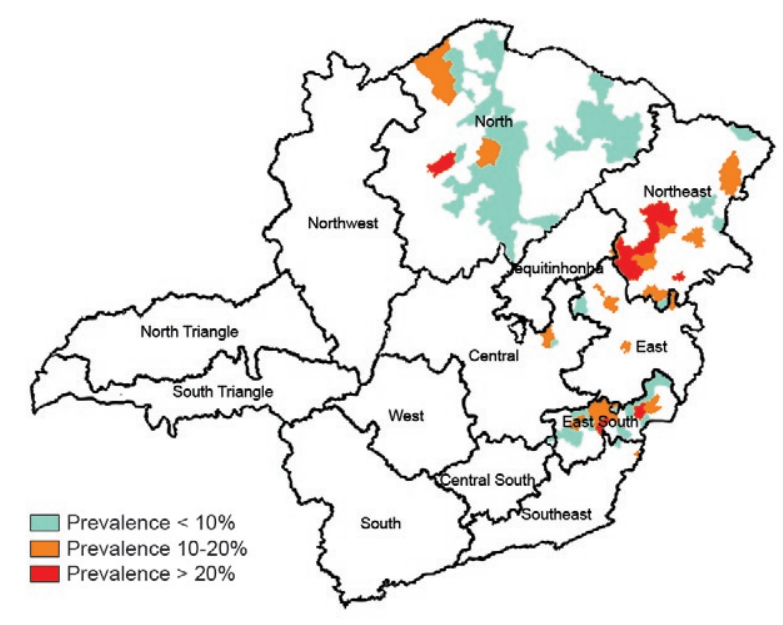

Fig. 3: prevalence of schistosomiasis infection in 81 municipalities of Minas Gerais, Brazil in evaluation 1 after treatment from 1984-2007.

somiasis (hepatosplenics, pulmonary hypertension, acute infection, extra-intestinal involvement) have become obligatory for all municipalities of MG.

In 1998, 265 patients were admitted to hospitals in MG because of schistosomiasis. In 2007, that number was reduced to 143 . The number of deaths attributed to schistosomiasis in 1996 was 32. In 2001 and 2005, 52 and 62 deaths, respectively, have been attributed to schistosomiasis.

Life in the Valley Project - This project will be implemented in 92 municipalities of the Jequitinhonha, Mucuri and São Mateus valleys from 2007-2010 (Fig. 5). For these areas, a more comprehensive approach has been planned to decrease the prevalence of schistosomiasis. Coincidently, those are the municipalities with the lowest index of human development in the state. Therefore, different areas of the government (Basic Sanitary Company of Minas Gerais, Planning and Management Secretary of state and the Foundation for Development and Research of the Federal University of Minas Gerais) will work together to improve housing, provide potable water and build sewage systems of adequate quality in these municipalities. One objective of this project is the reduction in the prevalence of schistosomiasis to below $10 \%$. 

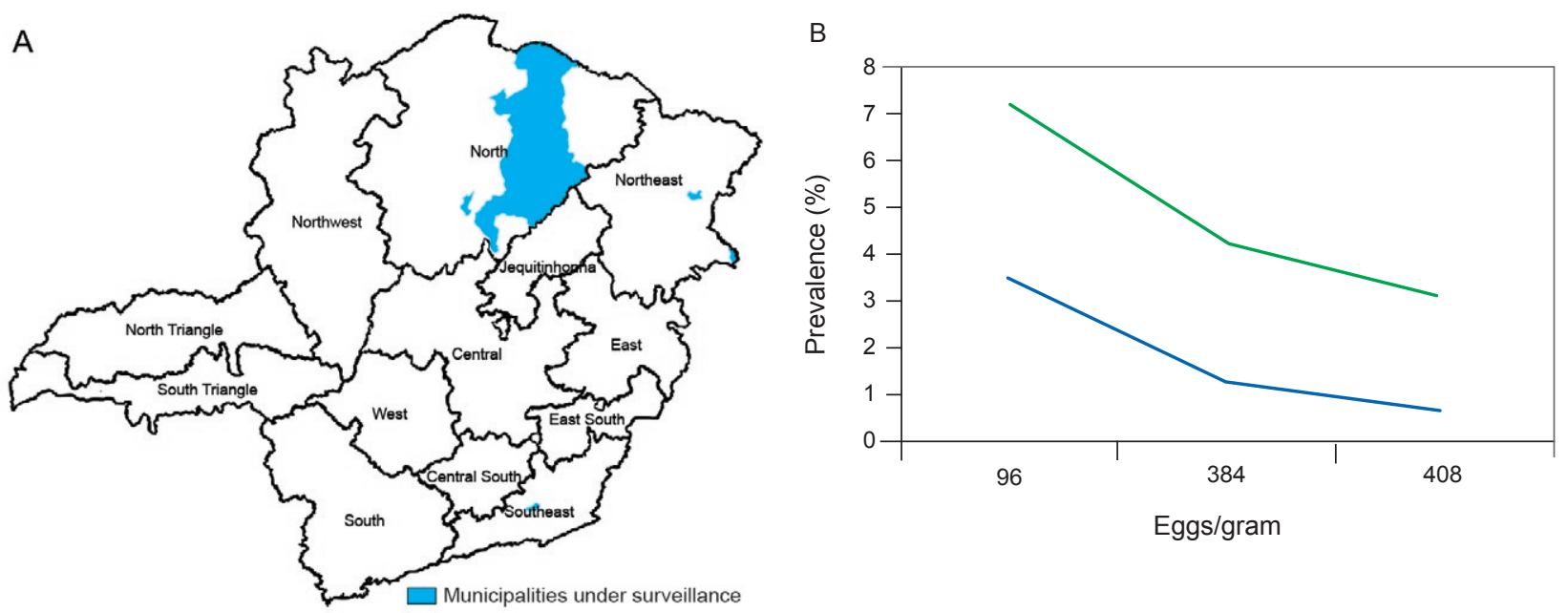

Fig. 4A: areas in Minas Gerais, Brazil under surveillance (prevalence $<10 \%$ ); B: the green line shows the prevalence and number of eggs/gram of faeces before treatment and the blue line the same parameters after praziquantel treatment.

\section{DISCUSSION}

In 256 municipalities of $\mathrm{MG}$, a significant decrease in prevalence and egg count in stool samples was documented in the first evaluation after treatment. The percentage of positive tests for schistosomiasis in the state was found to be $5.3 \%$. Northeast of MG is the area with the highest prevalence of schistosomiasis. From 20022008, a reference centre in Belo Horizonte examined 102 patients with hepatosplenic schistosomiasis and 61 with myeloradiculopathy.

In 1950, the prevalence of schistosomiasis in MG was $4.9 \%$ (Pellon \& Teixeira 1950) and, in 1977, it was 9.6\% (Katz et al. 1978). From 2003-2007, the percentage of positives was $5.3 \%$. What immediately caught our attention was that the general picture has not changed significantly. Even considering differences in the techniques used for stool examination, the population surveyed and data analysis, it is interesting that the general picture remains unchanged. MG has adhered to the control program since 1983 and probably did not share the benefit of mass chemotherapy used in the first years of the PECE. This may explain the small variation of prevalence over this period of 49 years.

During the survey of Pellon and Teixeira (1950), the Mucuri valley presented the highest prevalence of schistosomiasis in the state. For example, the prevalence of schistosomiasis for Itaipé, Rubim, Medina, Pedra Azul and Novo Cruzeiro was over $60 \%$ based on one parasitological stool examination. In the present study, it was not possible to obtain the information for these municipalities, but the general prevalence northeast of the state remains high (over 20\%).

Of note is the fact that in those areas subjected to treatment and followed up with one evaluation, the percentage of positives decreased significantly. The local health agents did well in areas where they became involved in the control program. This means that after decentralisation, the control program was successful using a novel strategy (the locality deals with their own health problems). We regret the fact that only $32 \%$ of the municipalities followed

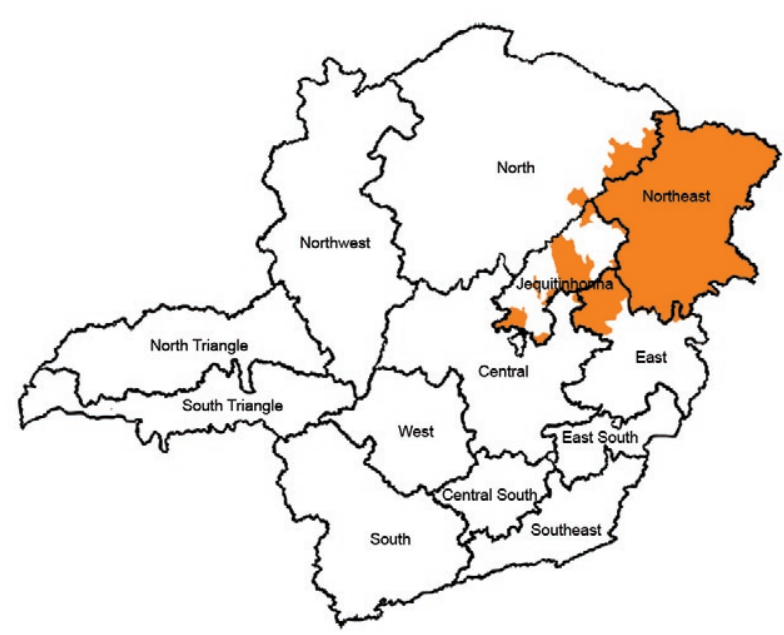

Fig. 5: municipalities of Minas Gerais, Brazil selected for the Life in the Valley Project in orange.

the recommendations for control of schistosomiasis and worked in collaboration to reach the goals set forth by the different levels involved in health care.

It is worth mentioning that in $\mathrm{MG}$, the municipalities are placed under surveillance when the prevalence decreases below $10 \%$. This approach differs from the proposed directives of the Ministry of Health of Brazil, which uses the locality (prevalence below 5\%) as the epidemiological unit for defining the prevalence of schistosomiasis. However, this makes it difficult to compare places that follow the national recommendations with MG. Notwithstanding, we admit that using the locality as the basic epidemiological unit for prevalence would be more appropriate because schistosomiasis has a focal distribution and the prevalence in the municipality may not reflect the prevalence in each locality. Regrettably, for $\mathrm{MG}$, this guidance has not yet been applied.

For the first time in the history of schistosomiasis control in Brazil, MG launched a program of surveillance of morbidity for schistosomiasis. From 2002-2008, 102 hepatosplenics and 61 patients with schistosomal 
myeloradiculopathy were assisted by health agents from different localities in the state and advised to seek help in a reference centre for schistosomiasis in Belo Horizonte (Drummond et al. 2006). Most patients received timely care, which prevented potential severe complications (Lambertucci et al. 2008a, b).

It is also important to emphasise the active search for solutions in areas where the control of schistosomiasis has been difficult. With a new approach called Life in the Valley Project, the control will include medical assistance and effective sanitary programs (housing, water supply, sewage systems) already supported financially by different institutions.

The number of patients admitted to hospitals decreased during the period of analysis, which is similar to what has been described for the whole country (Amaral et al. 2006). The interpretation of this phenomenon is difficult; however, it has been attributed by many investigators to the PCE (mostly to mass chemotherapy). Other explanations have also been suggested, such as a decrease in poverty and improvement in techniques for diagnosis and treatment. A good example is the surgical treatment of patients with hepatosplenic schistosomiasis. Fifteen years ago, patients used to be operated on because they had hepatosplenic schistosomiasis (prophylactic surgery), a practice that has been banned from medical practice. Currently, surgical indication is restricted to patients who have upper digestive bleeding, huge spleens or anaemia caused by hypersplenism. In addition, the introduction of routine sclerotherapy of oesophageal varices has postponed or prevented surgery in a large number of patients previously considered surgical cases.

Even considering the low quality of the data provided by the Health Department of Brazil on schistosomiasis, we conclude that the implementation of PCE in MG is on the right path and, in due time, these new initiatives (decentralisation and active search for solutions in areas of difficult control) will present the desired results, namely, to reduce the prevalence of the disease below $10 \%$ and decrease morbidity with early diagnosis and treatment. Actions are also being taken to provide the best care to those who are already sick and provide education for health as a way to reduce the transmission of the infection.

\section{REFERENCES}

Amaral RS, Porto MAS 1994. Evolução e situação atual da esquistossomose no Brasil. Rev Soc Bras Med Trop 27 (Suppl. 3): 73-90.

Amaral RS, Tauil PL, Lima DD, Engels D 2006. An analysis of the impact of the Schistosomiasis Control Programme in Brazil. Mem Inst Oswaldo Cruz 101 (Suppl. I): 79-85.

Drummond SC, Silva LCS, Amaral RS, Sousa-Pereira SR, Antunes CM, Lambertucci JR 2006. Morbidity of schistosomiasis mansoni in the state of Minas Gerais, Brazil. Mem Inst Oswaldo Cruz 101 (Suppl. I): 37-44.

Katz N, Mota E, Oliveira VB, Carvalho EF 1978. Prevalência de esquistossomose em escolares de Minas Gerais. Resumos do XIV Congresso da Sociedade Brasileira de Medicina Tropical, João Pessoa, p. 102.

Lambertucci JR 1993. Schistosoma mansoni: pathological and clinical aspects. In P Jordan, G Webbe, RF Sturrock (eds.), Human schistosomiasis, Cab International, Wallingford, p. 195-225.

Lambertucci JR, dos Santos Silva LC, Andrade LM, de Queiroz LC, Carvalho VT, Voieta I, Antunes CM 2008a. Imaging techniques in the evaluation of morbidity in schistosomiasis mansoni. Acta Trop 108: 209-217.

Lambertucci JR, Rayes AA, Serufo JC, Nobre V 2001. Pyogenic abscesses and parasitic diseases. Rev Inst Med Trop Sao Paulo 43: 67-74.

Lambertucci JR, Rocha RS, Carvalho OS, Katz N 1987. A esquistossomose mansoni em Minas Gerais. Rev Soc Bras Med Trop 20: 47-52.

Lambertucci JR, Serufo JC, Gerspacher-Lara R, Rayes AA, Teixeira R, Nobre V, Antunes CM 2000. Schistosoma mansoni: assessment of morbidity before and after control. Acta Trop 77: 101-109.

Lambertucci JR, Silva LC, do Amaral RS 2007. Guidelines for the diagnosis and treatment of schistosomal myeloradiculopathy. Rev Soc Bras Med Trop 40: 574-581.

Lambertucci JR, Voieta I, Silveira I dos S 2008b. Cerebral schistosomiasis mansoni. Rev Soc Bras Med Trop 41: 693-694.

Machado P 1982. The Brazilian Program for Schistosomiasis Control, 1975-1979. Am J Trop Med Hyg 31: 76-86.

Pellon AB, Teixeira I 1950. Distribuição geográfica da esquistossomose mansônica no Brasil. Ministério da Educação e Saúde, Rio de Janeiro, 24 pp.

Pirajá da Silva MA 1908. Contribuição para o estudo da schistosomiase na Bahia. Bras Med 22: 281-283. 